\title{
Erdbeere ist ethisch korrekt
}

\section{Rouven Porz}

PD Dr. phil., dipl. biol., Direktion Medizin, Medizinethik und ärztliche Weiterbildung Insel Gruppe AG (Bern), Präsident der European Association of Centres of Medical Ethics (EACME) und Mitglied der Redaktion Ethik der SÄZ

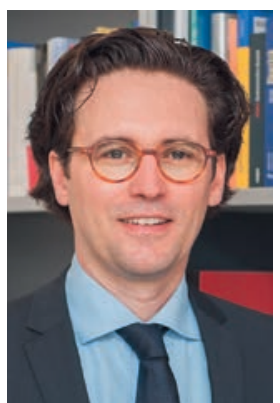

Es passiert mir noch relativ oft. So auch letzte Woche. Ich treffe einen einigermassen guten Bekannten von mir und er begrüsst mich mit den Worten: «Du, gut, dass ich dich sehe. Du bist doch Ethiker. Du musst mir helfen. Ich kann mich gerade nicht entscheiden. Was soll ich tun?» Ich wusste natürlich noch gar nicht, um was es ihm eigentlich geht, aber schon - deformation professionelle - ging es gedanklich mit mir durch.

Gute Entscheidungen, Werte, gutes Handeln, ja genau, das sind natürlich die Grundthemen der westlichen Ethik der letzten zweieinhalbtausend Jahre. Aber gleichzeitig gibt es auch kein allgemeingültiges, immer

Es gibt kein allgemeingültiges, immer anwendbares Patentrezept, wie man zu guten Entscheidungen kommt.

anwendbares Patentrezept, wie man zu guten Entscheidungen kommt. Wie man sich entscheidet, aus philosophischer Sicht, das hängt natürlich auch davon ab, zu welcher philosophisch-ethischen Schule man neigt, welche Ethiktheorien einem sympathisch sind. Ist man zum Beispiel ein Fan des altgriechischen Philosophen Aristoteles, dann geht man eher davon aus, dass man gute Entscheidungen wie Sport trainieren kann, dass es einen Unterschied zwischen sogenannten «Verstandestugenden» und «Charaktertugenden" gibt und dass einem die Verstandestugend der «Klugheit» nach reichhaltigem Training irgendwann ziemlich gut und intuitiv bei den guten Entscheidungen und Feinjustierungen der Charaktertugenden hilft. Es gab aber auch mal eine Zeit, deren Denkströmungen man heutzutage meist als Utilitarismus bezeichnet, wo gute Entscheidungen konzeptuell dadurch gekennzeichnet waren, dass durch die Entscheidung möglichst viele Leute glücklich gemacht werden sollten. Ganz anders wiederum bei Immanuel Kant, einem enorm wichtigen Vorreiter unserer kontinentalen Art, über Ethik nachzudenken. Ihm ging es eher um feste, unhinterfragbare Prinzipien, und nach diesen Prinzipien müsste man deontologisch Entscheidungen treffen.

Im Gesundheitssystem machen wir es uns mit den Entscheidungen ja relativ einfach. Verstehen Sie mich bitte nicht falsch. Wir gehen konzeptionell davon aus, dass der Patient bzw. die Patientin am besten weiss, was mit ihm oder ihr gemacht werden soll. Und deshalb steht bei gesundheitlichen Entscheidungen immer der Patientenwille im Vordergrund. Ob medizinische Laien überhaupt dazu in der Lage sind, zu verstehen, wie sich ihre Prognose, Diagnose, Therapie darstellt, das steht natürlich auf einem ganz anderen Blatt geschrieben. Manchmal wird dann eben genau diese Kritik laut. Kann man epistemologisch überhaupt von der Selbstbestimmung der Patienten ausgehen? Oder müsste man nicht vielmehr ihre Vulnerabilität bzw. Abhängigkeit vom Gesundheitssystem in den Entscheidungen in den Vordergrund stellen? Und ist sich der Arzt überhaupt seiner Berufsrollekonstitutiven Macht gegenüber kranken Menschen bewusst, oder nehmen Ärzte ihre implizite Macht in Entscheidungsprozessen gar nicht wahr?

«Was ist jetzt? Wie soll ich mich entscheiden? Himbeere oder Vanille?» Ich realisiere gerade, dass mich meine Gedanken fortgetragen haben und ich meinem Bekannten gar nicht mehr richtig zugehört habe. Und

\section{Nehmen Ärzte ihre implizite Macht in Entschei- dungsprozessen wahr?}

er hatte es gar nicht ernst gemeint, er wollte nur einen Spass mit mir machen. Ich sollte ihm nur sagen, für welche Eissorte er sich bei diesen hochsommerlichen Temperaturen entscheiden soll. "Ja, wie meinst du jetzt, vegan oder nachhaltig produziert?», frage ich naiv nach. Er lacht, das sei im egal. Welche Eissorte würde der Ethiker empfehlen? Ich finde es gerade gar nicht mehr lustig. Werden eigentlich alle Berufsgruppen immer so auf die Schippe genommen, oder geht das nur mir so? Die Entscheidung, ob ich Himbeere oder Vanille bestelle, ist per se keine moralische Handlung, ausser wenn man natürlich ... Egal jetzt, ich will mich nicht wieder gedanklich wegtragen lassen. Ich muss an meine fünfährige Tochter denken und was sie jetzt bestellen würde. "Erdbeere» sage ich, "Erdbeere ist ethisch korrekt.» Jetzt muss ich selber lachen. 